\title{
MULTILINGUALISME DI DUA DAYA TARIK WISATA IKONIK DI KAWASAN BANDUNG UTARA
}

\author{
Cep Ubad Abdullah ${ }^{1}$, Shandra Rama Panji Wulung ${ }^{2}$ \\ ${ }^{1}$ Universitas Pendidikan Indonesia, cepubad@upi.edu \\ ${ }^{2}$ Universitas Pendidikan Indonesia, wulung@upi.edu
}

\begin{abstract}
ABSTRAK
Pentingnya multilingulisme pada aktivitas pariwisata dipicu oleh adanya hambatan komunikasi dan budaya antara pengelola daya tarik wisata dengan wisatawan. Penelitian ini bertujuan untuk mengidentifikasi program-program yang telah dilakukan oleh pengelola daya tarik wisata di Kawasan Bandung Utara. Penelitian ini dilakukan selama empat bulan di tahun 2020 dan dilaksanakan di kawasan pariwisata di Bandung Utara yang difokuskan pada dua daya tarik ikonik yaitu Taman Wisata Alam Gunung Tangkubanparahu dan Tebing Keraton. Penelitian ini menggunakan pendekatan kualitatif dengan menggunakan data primer dan sekunder. Data primer didapatkan melalui observasi lapangan dan wawancara dengan pengelola dua daya tarik wisata. Data sekunder didapatkan melalui penelitian terdahulu, kebijakan pemerintah setempat, dan media digital melalui situs web dan media sosial. Metode analisis menggunakan analisis deskriptif kualitatif melalui tahapan analisis sebelum di lapangan, reduksi data, penyajian data, dan penarikan kesimpulan. Hasil penelitian menunjukkan bahwa daya tarik wisata Tebing Keraton dan TWA Tangkubanparahu memiliki komunikasi multi bahasa melalui media daring dan luring. Pesan yang disampaikan mengenai kondisi, posisi, dan peraturan bagi wisata selama di daya tarik wisata.
\end{abstract}

Kata kunci: $\quad$ Daya tarik wisata, Gunung Tangkubanparahu, Multilingualisme, Tebing Keraton

\begin{abstract}
The importance of multilingualism in tourism activities is due to communication and cultural barriers between managers of tourist attractions and tourists. This study aims to identify programs that have been carried out by managers of tourist attractions in the North Bandung area, Indonesia. This study had been for four months in 2020 and carried out in a tourism area in North Bandung which focused on two iconic attractions, namely the Tangkubanparahu Mountain Nature Tourism Park and the Tebing Keraton. This study used a qualitative approach featuring primary and secondary data. The primary data were obtained through observations and interviews with managers of two tourist attractions., while the secondary data were obtained through previous research, local government policies, and digital media through websites and social media. In the meantime, the method of analysis used qualitative descriptive analysis through the stages of analysis before coming to the field, data reduction, data presentation, and conclusion drawing. The results showed that the tourist attractions of Tangkubanparahu Mountain Nature Tourism Park and Tebing Keraton have multi-language communications through online and offline media. The message conveyed was regarding the conditions, position, and regulations for the tour while at the tourist attraction.
\end{abstract}

Keywords: Multilingualism, Mount Tangkubanparahu, Tebing Keraton, Tourist Attraction

ISSN: 2355-6587, e-ISSN: 2528-2220

http://ejournal.bsi.ac.id/ejurnal/index.php/jp 


\section{PENDAHULUAN}

Pariwisata menjadi salah satu sektor ekonomi berkontribusi signifikan pada perekonomian global dan menjadi hal yang sering diperdebatkan dan diteliti (Brauer et al., 2019; Perles-Ribes et al., 2017; Ruhanen et al., 2019; Tang \& Tan, 2018; Yung \& Khoo-Lattimore, 2019). Kajian terkait pariwisata dan linguistik akhir-akhir ini telah banyak diteliti oleh para peneliti, diantaranya Manaliyo (2009) yang mengkaji keterkaitan antara multibahasa dengan aktivitas pariwisata di Cape Town, Arfika Selatan; Wu et al. (2019) yang mengkaji kerangka pariwisata berkelanjutan berbasis preferensi linguistik; Pratiwi (2019) menganalisis linguistik dan kepariwisataan di Provinsi Bali, Indonesia; dan Yan (2019) mengkaji pemilihan bahasa wisatawan di destinasi Macao, Hongkong. Pentingnya pemilihan dan penggunaan bahasa pada aktivitas pariwisata menjadi suatu hal yang wajib diimplementasikan oleh pengelola destinasi pariwisata, terutama pengelola daya tarik wisata (Cameron, 2000; Cohen \& Cooper, 1986; Duchêne, 2009).

Keragaman bahasa di seluruh dunia menjadi hambatan pada suatu destinasi pariwisata. Adanya persepsi bahwa bahasa Inggris adalah bahasa bisnis internasional dan bahasa itu mendominasi bahasa lain di dunia (Arsky \& Cherny, 1997; Granville et al., 1998; Granville, 2003), asumsi tersebut dipertanyakan dalam bisnis pariwisata (Manaliyo, 2009). Alternatif solusi dapat dilakukan melalui program multibahasa dan multikultural yang dilakukan oleh industri pariwisata melalui pengelolaan sumber daya manusia pariwisata (Jafari \& Way, 1994; Pek et al., 2019). Jumlah penyedia layanan pariwisata yang mengakui keanekaragaman bahasa dan budaya di seluruh dunia meningkat secara signifikan, mereka memasarkan dan menjual produk mereka dalam berbagai bahasa (Lituchy \& Barra, 2008).

Pemilihan dan penggunaan bahasa dilembagakan dengan mendefinisikan bahasa mana yang harus diucapkan oleh siapa dan dengan siapa, dan dengan demikian mereka melayani dengan memberikan layanan kepada wisatawan (Duchêne, 2009). Penggunaan bahasa ini tidak dapat dipisahkan pada aspek budayanya, sehingga para pramuwisata yang mampu menguasai berbagai bahasa mampu beradaptasi dengan berbagai budaya. Oleh karena ini, hambatan bahasa, seperti yang diketahui semua orang, merupakan hambatan penting bagi komunikasi lintas budaya. Wisatawan sangat menyadari kesulitan ini, yang memiliki efek penting pada pilihan destinasi prospektif mereka, persiapan mereka untuk perjalanan, ruang lingkup dan isi interaksi mereka dengan penduduk setempat, dan kualitas pengalaman mereka (Cohen \& Cooper, 1986).

Diantara praktik dan jasa pariwisata adalah kunjungan wisatawan ke berbagai destinasi, baik nusantara dan mancanegara. Dalam kunjungan wisatawan tersebut, industri pariwisata memainkan peranan yang sangat penting. Industri pariwisata di era revolusi industri 4.0 dituntut untuk menguasai dua bahasa (bilingual) atau bahkan lebih banyak (multilingual). Hal ini mengingat bahwa multilingualisme itu sendiri telah menjadi komoditas mengingat fakta bahwa berinteraksi dalam bahasa wisatawan adalah faktor pemasaran utama (Sennett, 2000). Dalam beberapa tahun terakhir, sosiolinguistik dan antropolog linguistik telah menjawab pertanyaan sentral terkait dampak globalisasi pada praktik bahasa dan standardisasi mereka. Perhatian khusus telah diberikan pada semakin pentingnya bahasa dan komunikasi sebagai alat untuk pengaturan pola komunikasi, standardisasi varietas bahasa, dan penampilan identitas (Cameron, 2000).

Pentingnya mengkaji bahasa dalam aktivitas pariwisata diakibatkan adanya hambatan komunikasi dan budaya antara pengelola daya tarik wisata, wisatawan, dan masyarakat setempat. Bahasa menjadi hambatan penting dalam berkomunikasi lintas budaya bagi wisatawan selama di destinasi (Cohen \& Cooper, 1986). Kemampuan dan kualitas bahasa wajib diimplementasikan oleh pengelola daya tarik wisata melalui 
berbagai media dengan tujuan untuk menyampaikan pesan dan memberikan kesan pada pengalaman berwisata wisatawan (Aikhenvald, 2003; Arsky \& Cherny, 1997). Selain itu, penerapan multibahasa di daya tarik wisata bertujuan agar wisatawan dapat mengerti apa makna pesan yang disampaikan (Suhaimi \& Abdullah, 2017).

Kawasan Bandung Utara memiliki keberagaman daya tarik wisata, baik itu daya tarik berbasis alam, budaya, dan buatan (Ervina, et al., 2020; Fatmawatie \& Baizal, 2019; Wulung \& Brahmantyo, 2019), dua diantarnya yaitu Tebing Keraton dan Taman Wisata Alam Gunung Tangkubanparahu (Kartika \& Riana, 2020; Marhaento et al., 2020; Novianti et al., 2020; Wulung, 2018). Selama lima tahun terakhir, kunjungan wisatawan mancanegara ke Bandung mengalami peningkatan dari total 183.932 wisatawan mancanegara pada tahun 2015 menjadi 198.923 di tahun 2018 (BPS Kota Bandung, 2020). Hal tersebut menjadi tantangan bagi setiap pengelola daya tarik wisata di Kawasan Bandung Utara untuk mempersiapkan program-program multilingualisme sebagai penunjang aktivitas wisatawan mancanegara. Penelitian ini bertujuan untuk mengidentifikasi program-program yang telah dilakukan oleh pengelola daya tarik wisata di Kawasan Bandung Utara, khususnya Tebing Keraton dan Taman Wisata Alam Gunung Tangkubanparahu.

\section{KAJIAN LITERATUR}

Bilingualisme diartikan sebagai kemampuan individu dalam menggunakan dua atau lebih bahasa dengan baik sebagai alat komunikasi (Bloomfield, 1933), sementara multilingualisme merupakan kapasitas individu dan masyarakat dalam menggunakan lebih dari satu bahasa melalui berbagai media (Franceschini, 2009; McArthur et al., 2018). Multilingualisme lebih kepada kondisi individu dalam menguasai dan mengkomunikasi-kan kepada orang lain menggunakan lebih dari satu bahasa (Cummins, 2007; Duchêne, 2009). Masyarakat modern harus mampu menguasai lebih dari satu bahasa sebagai alat untuk berinteraksi sosial sesuai situasi dalam berkomunikasi (Cummins, 2007; Wahyudi \& Widhiasih, 2016). Manaliyo, (2009) menjelaskan bahwa terdapat beberapa indikator upaya multilingualisme daya tarik wisata, diantaranya keragaman bahasa yang digunakan, karyawan yang menggunakan multi bahasa, media komunikasi yang digunakan, dan ketersediaan pramuwisata.

Franceschini mendefinisikan multilingualisme sebagai kapasitas masyarakat, kelompok, lembaga dan individu untuk beroperasi dalam lebih dari satu bahasa. Menurut (McArthur et al., 2018) multibahasa adalah penggunaan tiga bahasa lebih baik secara terpisah dalam berbagai tingkat pencampuran kode. Multilingual dapat menggunakan sejumlah bahasa karena berbagai alasan sosial, budaya, dan ekonomi. Bahasa yang berbeda digunakan untuk tujuan dan kompetensi yang berbeda untuk masingmasing bahasa. Di sisi lain, (Kemp, 2009) menghindari memberikan hitungan bahasa yang tepat dengan mendefinisikan multibahasa sebagai menggunakan sejumlah bahasa karena berbagai alasan sosial, budaya, dan ekonomi. Menurut Cummins (2007), multilingualisme merujuk secara eksklusif pada kehadiran beberapa bahasa dalam ruang yang diberikan, terlepas dari mereka yang menggunakannya. Multilingualisme lebih pada penggambaran seorang penutur yang menguasai lebih dari dua bahasa. Penggunaannya hampir sama dengan bilingualisme, yakni tahu kapan dan dimana suatu bahasa akan digunakan. multilingual adalah masyarakat yang mempunyai atau menggunakan beberapa bahasa dalam kegiatannya (Duchêne, 2009).

Fungsi bahasa sebagai alat komunikasi menunjukkan bahwa masyarakat pada masa sekarang tidak hanya mengenal atau menguasai penggunaan satu bahasa saja, namun mereka telah mau dan mampu menguasai dua bahasa atau lebih. Situasi ini menunjukkan bahwa mereka merupakan masyarakat bilingual atau multilingual. 
Interaksi sosial dalam masyarakat aneka bahasa, dengan tersedianya beberapa bahasa atau ragam bahasa menuntut tiaptiap penutur mampu memilih secara tepat bahasa atau ragam bahasa yang sesuai dengan situasi komunikasi (Wahyudi \& Widhiasih, 2016).

\section{METODE PENELITIAN}

Penelitian ini dilakukan selama 4 bulan dari Juli hingga Oktober 2020 dan dilaksanakan di kawasan pariwisata di Bandung Utara yang difokuskan pada dua daya tarik ikonik yaitu Taman Wisata Alam Gunung Tangkubanparahu dan Tebing Keraton. Pendekatan yang digunakan pada penelitian ini adalah penelitian kualitatif yang bertujuan untuk mengeksplorasi dan memahami makna dari aktivitas pariwisata dan kaitannya dengan program multilingualisme di daya tarik wisata melalui keterlibatan beberapa pertanyaan dan prosedur.

Penelitian ini menggunakan data primer dan sekunder. Data primer didapatkan melalui observasi lapangan dan wawancara dengan pengelola dua daya tarik wisata.. Wawancara difokuskan pada upaya pengelola daya tarik wisata dalam mengimplementasikan program-program multilingualisme sebagai sarana bagi wisatawan mancanegara. Data sekunder didapatkan melalui penelitian terdahulu, kebijakan pemerintah setempat, dan media digital melalui situs web dan media sosial. Metode analisis menggunakan analisis deskriptif kualitatif melalui tahapan analisis sebelum di lapangan, reduksi data, penyajian data, dan penarikan kesimpulan.

\section{PEMBAHASAN}

Perkembangan daya tarik wisata dari indikator kunjungan wisatawan di Kawasan Bandung Utara lebih unggul pada destinasi pariwisata Kota Bandung, hal tersebut dikarenakan adanya kesadaran wisatawan yang cenderung tertarik pada kondisi dan kualitas lingkungan Kawasan Bandung Raya yang masih terjaga untuk melakukan aktivitas wisata seperti relaksasi, jalan santai, dan bersepeda (Ervina, et al., 2020). Akumulasi antara wisatawan mancanegara dan nusantara di Kawasan Bandung Utara jauh di atas destinasi pariwisata lainnya baik pada tahun 2018 ataupun pada tahun 2019 (BPS Kota Bandung, 2020; BPS Provinsi Jawa Barat, 2021). Pengelolaan kepariwisataan di Kawasan Bandung Utara pada dasarnya di bawah wewenang Pemerintah Provinsi Jawa Barat melalui Dinas Bina Marga dan Penataan Ruang, juga Badan Perencanaan Pembangunan Daerah yang mengatur Kawasan Bandung Utara sebagai kawasan strategis provinsi. Kemudian, sama seperti daerah lainnya di Indonesia, bahwa pemerintah daerah khususnya Organisasi Perangkat Daerah (OPD) kepariwisataan yaitu dinas pariwisata kota dan kabupaten yang memiliki otoritas dalam pengembangan pariwisata di daerahnya.

Di Kawasan Bandung Utara kepengelolaannya berada pada Dinas Pariwisata dan Kebudayaan Provinsi Jawa Barat, Dinas Kebudayaan dan Pariwisata Kota Bandung, Dinas Pariwisata dan Kebudayaan Kabupaten Bandung, dan Dinas Pariwisata dan Kebudayaan Kabupaten Bandung Barat. Pada praktiknya karena karakteristik KBU yang didominasi oleh alam, terdapat beberapa model tata kelola dibeberapa daya tarik wiata seperti Taman Hutan Raya Ir. H. Djuanda oleh Dinas Kehutanan, Pemerintah Daerah Provinsi Jawa Barat, dan Perum Perhutani. Kemudian Taman Wisata Alam Tangkuban Perahu dengan pola public private partnership (kerjasama antara pemerintah dengan swasta) karena secara swasta pengelolaan pariwisatanya dikelola oleh PT. Graha Rani Putra Persada dan secara publik berada di bawah naungan Balai Besar Konservasi Sumber Daya Alam Jawa Barat. 
Tabel 1

Upaya mulilingualisme di Daya Tarik Wisata Tebing Keraton dan Taman Wisata Alam Gunung Tangkubanparahu

\begin{tabular}{|c|c|c|c|c|}
\hline \multirow{2}{*}{$\begin{array}{r}\text { DAYA } \\
\text { TARIK } \\
\text { WISATA }\end{array}$} & \multicolumn{4}{|c|}{ MULTILINGUALISME } \\
\hline & $\begin{array}{c}\text { KERAGAMAN } \\
\text { BAHASA }\end{array}$ & KARYAWAN & PRAMUWISATA & $\begin{array}{c}\text { MEDIA } \\
\text { KOMUNIKASI }\end{array}$ \\
\hline $\begin{array}{l}\text { Tebing } \\
\text { Keraton }\end{array}$ & $\begin{array}{l}\text { Indonesia, } \\
\text { Inggris }\end{array}$ & $\begin{array}{l}\text { Tidak terdapat } \\
\text { karyawan yang } \\
\text { menguasai } \\
\text { Bahasa Inggris }\end{array}$ & $\begin{array}{l}\text { Ya (Indonesia, } \\
\text { Inggris) }\end{array}$ & $\begin{array}{ll}\text { Daring: Situs } \\
\text { web dan } \\
\text { media social } \\
\text { - Luring: } \\
\text { Brosur, } \\
\text { banner, dan } \\
\text { spanduk } \\
\end{array}$ \\
\hline $\begin{array}{l}\text { Taman } \\
\text { Wisata } \\
\text { Alam } \\
\text { Gunung } \\
\text { Tangkuban } \\
\text { parahu }\end{array}$ & $\begin{array}{l}\text { Indonesia, } \\
\text { Inggris. }\end{array}$ & $\begin{array}{l}\text { Ya, terdapat } \\
\text { karyawan yang } \\
\text { mampu } \\
\text { berbahasa } \\
\text { Inggris }\end{array}$ & $\begin{array}{l}\text { Ya (Indonesia, } \\
\text { Inggris, Belanda, } \\
\text { Jepang, dan } \\
\text { Jerman) }\end{array}$ & $\begin{array}{l}\text { Daring: Situs } \\
\text { web dan } \\
\text { media social } \\
\text { - Luring: } \\
\text { Brosur, } \\
\text { banner, } \\
\text { spanduk, dan } \\
\text { pengeras suara }\end{array}$ \\
\hline
\end{tabular}

Sumber : Diolah dari data primer (2020)

Tebing Keraton dan Taman Wisata Alam Gunung Tangkubanparahu menjadi dua daya tarik wisata ikonik di Kawasan Bandung Utara. Kedua daya tarik wisata diklasifikasikan sebagai daya tarik wisata berbasis alam. Tebing Keraton menjadi bagian dari Sesar Lembang yang memiliki tingkat kemiringan dengan lembah lurus dan memiliki panorama keindahan lanskap wilayah Lembang (Wulung \& Brahmantyo, 2019). Sementara Taman
Wisata Alam Gunung Tangkubanparahu merupakan kawasan gunung api yang masih aktif dan memiliki kawah dapat dikunjungi (Brahmantyo \& Bachtiar, 2009). Berbagai upaya dan programprogram multilingualisme telah dilakukan oleh kedua daya tarik wisata tersebut, baik itu melalui media komunikasi luar ruangan dan komunikasi digital (Tabel 1). Upaya tersebut untuk memfasilitasi wisatawan mancanegara dalam memaknai profil,

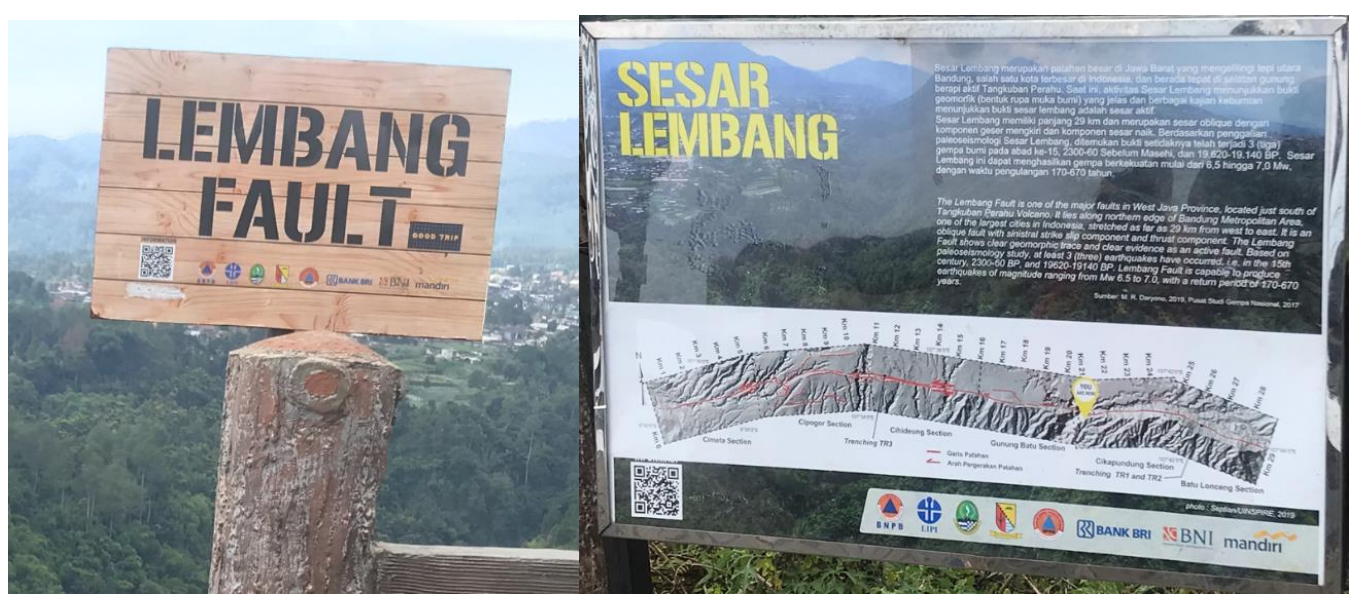

Gambar 1

Bahasa Indonesia dan Inggris dalam menginterpretasikan kondisi Daya Tarik Wisata

Tebing Keraton yang menjadi bagian dari Sesar Lembang

Sumber : Dokumentasi penelitian (2020)

ISSN: 2355-6587, e-ISSN: 2528-2220

http://ejournal.bsi.ac.id/ejurnal/index.php/jp 


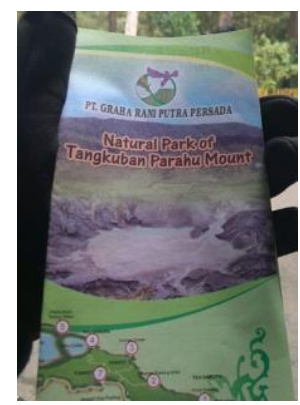

(a)

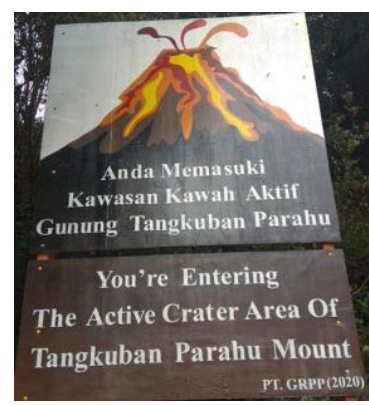

(b)

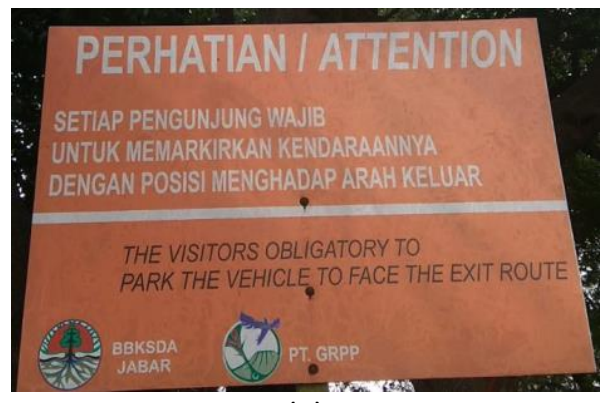

(c)

Gambar 2

Upaya multilingualisme yang dilakukan oleh pengelola Taman Wisata Alam Gunung Tangkubanparahu melalui media brosur sebagai informasi bagi wisatawan (a), banner tentang informasi area kawah (b) dan peraturan untuk wisatawan (c).

Sumber : Dokumentasi penelitian (2020)

sejarah, dan fitur yang terdapat di daya tarik wisata.

Daya tarik wisata Tebing Keraton memiliki komunikasi multi bahasa melalui media banner (Gambar 1). Pesan yang disampaikan mengenai kondisi dan posisisi Tebing Keraton yang merupakan bagian dari Sesar Lambang. Interpretasi yang terdapat dalam benner tersebut berbagahsa Indonesia dan Inggris. Sedangkan untuk media daring, Tebing Keraton yang masuk dalam pengelolaan Taman Hutan Raya Ir. H. Djuanda tidak melakukan upaya multi bahasa melalui media daring, seperti situs web (tahuradjuanda.jabarprov.go.id) dan media sosial (facebook.com/Tahuraid108053380545979

instagram.com/tahuradjuanda.official).

Taman Wisata Alam Gunung Tangkubanparahu melakukan upaya multilingualisme melalui media brosur dan banner (Gambar 2). Pada Gambar 2a, informasi yang diberikan dalam bentuk bahasa Indonesia dan Inggris mengenai profil dan kegiatan yang dapat dilakukan di Taman Wisata Alam Gunung Tangkubanparahu. Sementara pada Gambar 2c, terdapat peraturan bagi wisatawan melalui dua bahasa berbeda. Meskipun demikian, Taman Wisata Alam Gunung Tangkubanparahu tidak mengimplementasikan pada media daring. Seperti pada situs web (twatangkubanparahu.com) yang hanya menggunakan Bahasa Indonesia, begitu pula di media sosial Facebook (facebook.com/tangkuban.parahu.524), Instagram

(instagram.com/twa_tangkubanparahu), dan Twitter (twitter.com/twatangkuban).

\section{PENUTUP}

Penggunaan bahasa pada kepariwisataan telah menjadi salah satu faktor yang berpengaruh pada aktivitas wisata di Kawasan Bandung Utara. Bahasa yang baik dan beragam menjadi faktor penting bagi para daya tarik wisata dalam memasarkan produknya, hal tersebut bertujuan agar wisatawan mancanegara mudah memahami komunikasi. Selain itu, penggunaan multilingualisme di kawasan daya tarik wisata dapat membantu wisatawan mancanegara memahami makna dan maksud dari media yang telah disediakan. Di daya tarik wisata TWA Gunung Tangkubanparahu dan Tebing Keraton memiliki program mulitlingualisme dalam mendukung kepariwisataan di Kawasan Bandung Utara. Program mulilingualisme di dua daya tarik tersebut diimplementasikan melalui media daring dan luar ruangan.

Penelitian ini menjadi implikasi bagi pengelola daya tarik wisata Taman Wisata Alam Tangkubanparahu dan Tebing Keraton untuk lebih memperhatikan program-program multilingualisme sebagai upaya meningkatkan kepuasan bagi wisatawan mancanegara dan mendukung terwujudnya daya tarik wisata berdaya saing global. 
Selain itu, penelitian ini dapat menjadi acuan bagi pengelola daya tarik wisata lainnya di Kawasan Bandung Utara dan Indonesia umumnya.

Penelitian ini fokus pada multilingualisme di dua daya tarik wisata di Kawasan Bandung Utara. Hal tersebut menjadi keterbatasan pada penelitian ini. Penelitian lebih lanjut dapat dilakukan industri pariwisata di Kawasan Bandung Utara, seperti hotel dan restoran. Hal tersebut bertujuan untuk mengintegrasikan upaya multilingualisme di Kawasan Bandung Utara.

\section{REFERENSI}

Aikhenvald, A. Y. (2003). Multilingualism and ethnic stereotypes: The Tariana of northwest Amazonia. Language in Society, 32(1), 1-21. https://doi.org/10.1017/S0047404503 321013

Arsky, J. M., \& Cherny, A. I. (1997). The Ethno-Cultural, Linguistic and Ethical Problems of the "Infosphere." International Information \& Library Review, 29(2), 251-260. https://doi.org/10.1080/10572317.199 7.10762434

Bloomfield, L. (1933). Language history: from Language. Holt, Rinehart and Winston.

BPS Kota Bandung. (2020). Data kunjungan wisatawan mancenegara.

BPS Provinsi Jawa Barat. (2021). Data Kunjungan Wisatawan ke Daya Tarik Wisata di Jawa Barat. Jabar.Bps.Go.Id.

https://jabar.bps.go.id/indicator/16/22 0/1/jumlah-kunjungan-wisatawan-keobjek-wisata.html

Brahmantyo, B., \& Bachtiar, T. (2009). Wisata Bumi Cekungan Bandung (Bandung Basin Earth Tourism). TrueDee Pustaka Sejati.

Brauer, R., Dymitrow, M., \& Tribe, J. (2019). The impact of tourism research. Annals of Tourism Research, 77, 64-78. https://doi.org/10.1016/j.annals.2019. 05.006

Cameron, D. (2000). Styling the worker: \{Gender\} and the commodification of language in the globalized service economy. Journal of Sociolinguistics, 4(3), https://doi.org/10.1111/14679481.00119

Cohen, E., \& Cooper, R. L. (1986). Language and tourism. Annals of Tourism Research, 13(4), 533-563. https://doi.org/10.1016/0160$7383(86) 90002-2$

Cummins, J. (2007). Rethinking monolingual instructional strategies in multilingual classrooms. Canadian Journal of Applied Linguistics, 10(2), 221-240.

Duchêne, A. (2009). Marketing, management and performance: Multilingualism as commodity in a tourism call centre. Language Policy, $8(1), \quad 27-50$. https://doi.org/10.1007/s10993-0089115-6

Ervina, E., Octaviany, V., \& Wulung, S. R. P. (2020). Visitor management strategies in nature-based destination: A case study in Djuanda Forest Park, Bandung, Indonesia. Test Engineering and Management, 83, 7654-7660.

http://www.testmagzine.biz/index.ph $\mathrm{p} /$ testmagzine/article/view/5053

Ervina, E., Wulung, S., \& Octivany, V. (2020). Tourist Perception of Visitor Management Strategy in North Bandung Protected Area. Journal of Business on Hospitality and Tourism. https://doi.org/10.22334/jbhost.v6i2.2 35

Fatmawatie, B. D., \& Baizal, Z. K. A. (2019). Tourism recommender system using Case Based Reasoning Approach (Case Study: Bandung Raya Area). Journal of Physics: Conference Series, 1192(1). https://doi.org/10.1088/17426596/1192/1/012050

Franceschini, R. (2009). The genesis and development of research in multilingualism: Perspectives for future research. In The exploration of multilingualism: Development of research on L3, multilingualism, and multiple languange acquisition (Issue 
6, pp. 27-61). John Benjamis Publishing Company.

Granville, S., Janks, H., Mphahlele, M., Reed, Y., Watson, P., Joseph, M., \& Ramani, E. (1998). English with or without $\mathrm{g}(\mathrm{U}) \mathrm{ilt}$ : A position paper on language in education policy for south Africa. Language and Education, 12(4), 254-272. https://doi.org/10.1080/09500789808 666753

Granville, Stella. (2003). Contests over meaning in a south african classroom: Introducing critical language awareness in a climate of social change and cultural diversity. Language and Education, 17(1), 20. https://doi.org/10.1080/09500780308 666835

Jafari, J., \& Way, W. (1994). Multicultural Strategics in Tourism. Cornell Hotel and Restaurant Administration Quarterly, 35(6), 72-79. https://doi.org/10.1177/00108804940 3500614

Kartika, T., \& Riana, N. (2020). Storynomics Tourism as an Effective Marketing Strategy on Tourism Destination (Case Study on Tangkuban Parahu, West JavaIndonesia). Tourism and Sustainable Development Review, 1(1), 33-40. https://doi.org/10.31098/tsdr.v1i1.8

Kemp, C. (2009). Learning, transfer, and creativity in multilingual language learning: A dynamic systems approach. Proceeding of Third Language Acquisition and Multilingualism.

Lituchy, T. R., \& Barra, R. A. (2008). International issues of the design and usage of websites for e-commerce: \{Hotel\} and airline examples. Journal of Engineering and Technology Management, 25(1-2), 93-111.

https://doi.org/10.1016/j.jengtecman. 2008.01.004

Manaliyo, J. C. (2009). Tourism and multilingualism in Cape Town: language practices and policy.

Marhaento, H., Purnama, R., Rahayu Wijayanti Faida, L., \& Rahardjo, N.
(2020). Land cover disturbance due to tourism in Djuanda Forest Park, Indonesia. Journal of Physics: Conference Series, 1434(1). https://doi.org/10.1088/17426596/1434/1/012032

McArthur, T., Lam-McArthur, J., Fontaine, L., \& McArthur, R. (2018). The Oxford companion to the English language (T. McArthur, J. LamMcArthur, L. Fontaine, \& R. McArthur (eds.); Second edi). Oxford University Press.

Novianti, E., Endyana, C., Lusiana, E., Wulung, S. R. P., \& Desiana, R. (2020). Komunikasi Persuasif dan Penerapannya di Daya Tarik Wisata Tebing Keraton. Tornare. https://doi.org/10.24198/tornare.v2i3. 29694

Pek, L. S., Mee, R. W. M., Nadarajan, N. T. M., Mohamad, A. R., Alias, Z., \& Ismail, M. R. (2019). Tourists' Perceptions on Multilingualism use among Tourism Employees at Major Attractions in Kuala Selangor. International Journal of Academic Research in Business and Social Science, 9(5), 914-919.

Perles-Ribes, J. F., Ramón-Rodríguez, A. B., Rubia, A., \& Moreno-Izquierdo, L. (2017). Is the tourism-led growth hypothesis valid after the global economic and financial crisis? The case of Spain 1957-2014. Tourism Management, 61, 96-109. https://doi.org/10.1016/j.tourman.201 7.01.003

Pratiwi, D. P. E. (2019). Bali tourism advertisements: a linguistic analysis. International Journal of Linguistics, Literature and Culture. https://doi.org/10.21744/ijllc.v5n1.58 2

Ruhanen, L., Moyle, C. lee, \& Moyle, B. (2019). New directions in sustainable tourism research. Tourism Review, 74(2), 245-256. https://doi.org/10.1108/TR-12-20170196

Sennett, R. (2000). Le travail sans qualités: les conséquences humaines de la flexibilité. Albin Michel. 
Suhaimi, N. I. B., \& Abdullah, A. T. H. bin. (2017). The Role of Multilingualism in Enhancing Tourism Sector in Malaysia. International Journal of Academic Research in Business and Social Sciences, 7(7), Pages 816--832. https://doi.org/10.6007/IJARBSS/v7i7/3154

Tang, C. F., \& Tan, E. C. (2018). TourismLed Growth Hypothesis: A New Global Evidence. Cornell Hospitality Quarterly, 59(3), 304-311. https://doi.org/10.1177/19389655177 35743

Wahyudi, N. D., \& Widhiasih, L. K. S. (2016).

Keanekabahasaan

(Multilingualisme) dalam Video Promosi Destinasi Pariwisata Jegeg Bagus Denpasar. Prosiding Seminar Nasional Hasil Penelitian.

Wu, K. J., Zhu, Y., Chen, Q., \& Tseng, M. L. (2019). Building sustainable tourism hierarchical framework: Coordinated triple bottom line approach in linguistic preferences. Journal of Cleaner Production, 229, 157-168.

https://doi.org/10.1016/j.jclepro.2019 .04 .212

Wulung, S. R. P. (2018). Spatial Model Analysis of Bandung Basin Geotourism Destination [Bandung Institute of Technology]. https://digilib.itb.ac.id/gdl.php?mod= browse\&op=read\&id=jbptitbpp-gdlshandraram-28074

Wulung, S. R. P., \& Brahmantyo, B. (2019). Geotourism Reinterpretation towards Natural Tourist Attractions in Bandung Basin, West Java, Indonesia. 3rd International Seminar on $\quad . . . \quad$ https://www.atlantispress.com/proceedings/isot$18 / 125909398$

Yan, X. (2019). A study of language choices in the linguistic landscape of Macao's heritage and gaming tourism. Journal of Multilingual and Multicultural Development, 40(3), 198-217.

https://doi.org/10.1080/01434632.201 8.1498853
Yung, R., \& Khoo-Lattimore, C. (2019). New realities: a systematic literature review on virtual reality and augmented reality in tourism research. Current Issues in Tourism, 22(17), 2056-2081. https://doi.org/10.1080/13683500.201 7.1417359

\section{BIODATA PENULIS}

Cep Ubad Abdullah, staf pengajar di Program Studi Pendidikan Pariwisata, Universitas Pendidikan Indonesia. Alumnus (S1) Program Studi Pendidikan Bahasa Inggris, Universitas Pendidikan Indonesia dan mendapatkan gelar magister untuk bidang Pendidikan Basaha Inggris di Universitas Pendidikan Indonesia. Fokus kajian penelitiannya terkait multilingualisme pada industri pariwisata.

Shandra Rama Panji Wulung, staf pengajar di Program Studi Pendidikan Pariwisata, Universitas Pendidikan Indonesia. Alumnus (S1) Program Studi Manajemen Pemasaran Pariwisata, Universitas Pendidikan Indonesia dan mendapatkan gelar magister untuk bidang Perencanaan Kepariwisataan di Institut Teknologi Bandung. Fokus kajian penelitiannya terkait geowisata, pemasaran pariwisata, perencanaan kepariwisataan, dan manajemen bencana destinasi pariwisata. 